\title{
The Successful Use of Marsupialization of Maxillary Cysts and Benign Tumors Combined With Orthodontic Treatment
}

\author{
Afef Slim ${ }^{1 *}$, Hajer Hentati ${ }^{2}$, Inès Dallel ${ }^{2}$, Mounir Omami ${ }^{1}$, Adel Bouguezzi ${ }^{1}$, Abdellatif Chokri ${ }^{2}$, Jamil Selmi ${ }^{2}$
}

${ }^{1}$ Department Oral Surgery, University dental clinic, Monastir, Tunisia

${ }^{2}$ Laboratory of Research in Oral Health and Orofacial Rehabilitation, (LR12ES11), University of Monastir, Faculty of Dental Medicine, Tunisia

DOI: $10.36347 /$ sjams.2020.v08i10.039

| Received: 04.02.2020 | Accepted: 22.02.2020 | Published: 30.10.2020

*Corresponding author: Afef Slim

Abstract

Original Research Article

Introduction: We aimed through a systematic review of the literature to evaluate the effectiveness of marsupialization or decompression for cysts and benign cystic tumors of the jaw and to provide more information on the contribution of orthodontics to this conservative treatment. Articles and Methods: An electronic search on PubMed/MEDLINE and Cochrane Library databases was conducted using MeSH terms. The relevant articles published in English were identified after a review of their titles, abstracts and full reading of the papers. Results: Forty-six articles were included and analyzed. In this study, 1089 patients were included, with a total of 1101 lesions. Only 10 published articles dealt with the combined use of marsupialization of cystic lesions of the jaw and orthodontic treatment. Conclusion: Marsupialization or decompression could be performed as a single surgical procedure or combined with other treatment modalities for many cystic lesions of the jaws. It has been accepted and used as a conservative surgical option. Furthermore, combined orthodontic-surgical technique can be useful to promote the eruption of cyst-associated teeth. The long-term follow-up confirmed the treatment effectiveness.

Keywords: tumors, orthodontics, cyst-associated teeth.

Copyright $(\mathcal{C}) 2020$ The Author(s): This is an open-access article distributed under the terms of the Creative Commons Attribution 4.0 International License (CC BY-NC 4.0) which permits unrestricted use, distribution, and reproduction in any medium for non-commercial use provided the original author and source are credited.

\section{INTRODUCTION}

Cystic lesions (CL) are one of the most common pathologies affecting the jaws. Depending on the size of the CL, its location and the patients' age, several treatment options are available: curettage, enucleation, radical treatment and marsupialization [1]. Marsupialization can be used for primary treatment of large CL. It was first described by Partsch [2] in the German literature in the late $19^{\text {th }}$ century, a large window is created within the cyst bony wall and the cystic lining is sutured to the oral mucosa.

Thomas [3] modified Partsch's method. In this modification, a small opening is made in the defect and a drainage tube is inserted and fixed at the site. This technique was termed decompression. Marsupialization therapy is suggested to prevent the complications associated with a large CL of the jaw, and to promote the spontaneous eruption of the involved tooth within the cyst. However, tooth eruption does not always occur spontaneously after decompression.

Furthermore, combined orthodontic-surgical technique can be useful to promote the eruption of cystassociated teeth.
Since there were many cases reported in the literature, there is still not a summary to provide statistical analysis results. Therefore, this paper reviewed all the articles on marsupialization and decompression from the literature.

\section{MethODS}

\section{Search Strategy}

An electronic search was conducted using the PubMed/MEDLINE and The Cochrane Library databases. Databases were searched from the year 2009 up to December 2018, the research was later updated throughout the redaction of this systematic review until March 2019. Search keywords used were: 'Marsupialization', 'Maxillary cyst', 'Conservative treatment', Decompression', 'Impacted tooth', 'Jaw cyst', 'Dentigerous cyst', 'Orthodontic extrusion', 'Cyst management', 'orthodontic corrective', 'Adenomatoid odontogenic tumor', 'Keratocyst', 'Ameloblastoma', 'benign tumor', 'Maxilla' and 'Mandible'.

\section{Inclusion and Exclusion Criteria}

In this systematic review, the PICOS format was used, according to the preferred reporting items for systematic reviews and meta-analyses (PRISMA) 
guidelines [4], resulting in the following: Population: adult, young or elderly patients with cysts or benign cystic tumors of the jaw that were diagnosed and confirmed histologically; Intervention: Marsupialization or decompression with or without secondary enucleation and adjunctive therapy; Comparator: Not applicable; Outcome: The main outcome was the success of the intervention. Success is defined if the protocol was effective in preserving the important anatomical structures and the associated permanent teeth and led to absence of recurrence; Study design:
Randomized controlled trial, retrospective and prospective cohorts, case reports, case series and systematic reviews.

Articles not included in the study were those written in non-English language, those on the pathologic analysis of the CL, those on the osteogenesis evaluation, and those which contents do not answer the search question. This is further described in the following monograph (Fig-1).
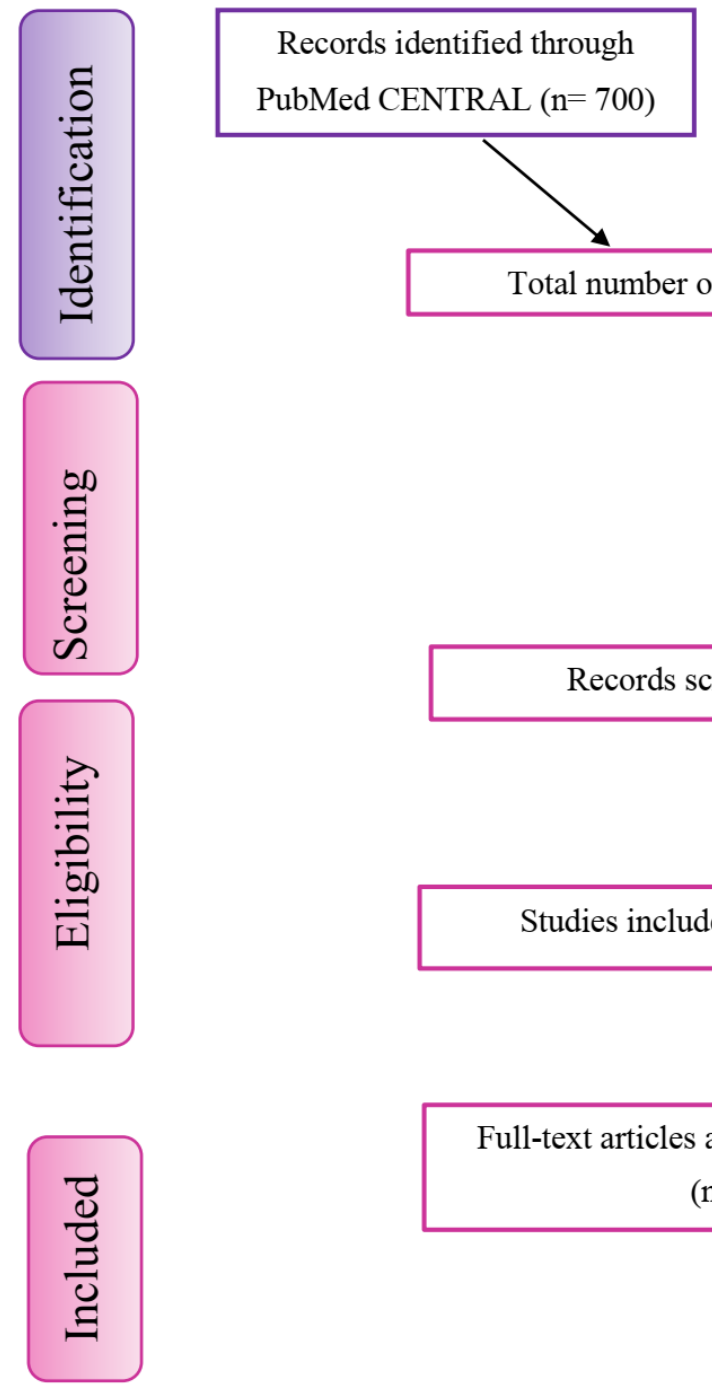

\section{Records identified through \\ Cochrane Central Register $(\mathrm{n}=4)$}

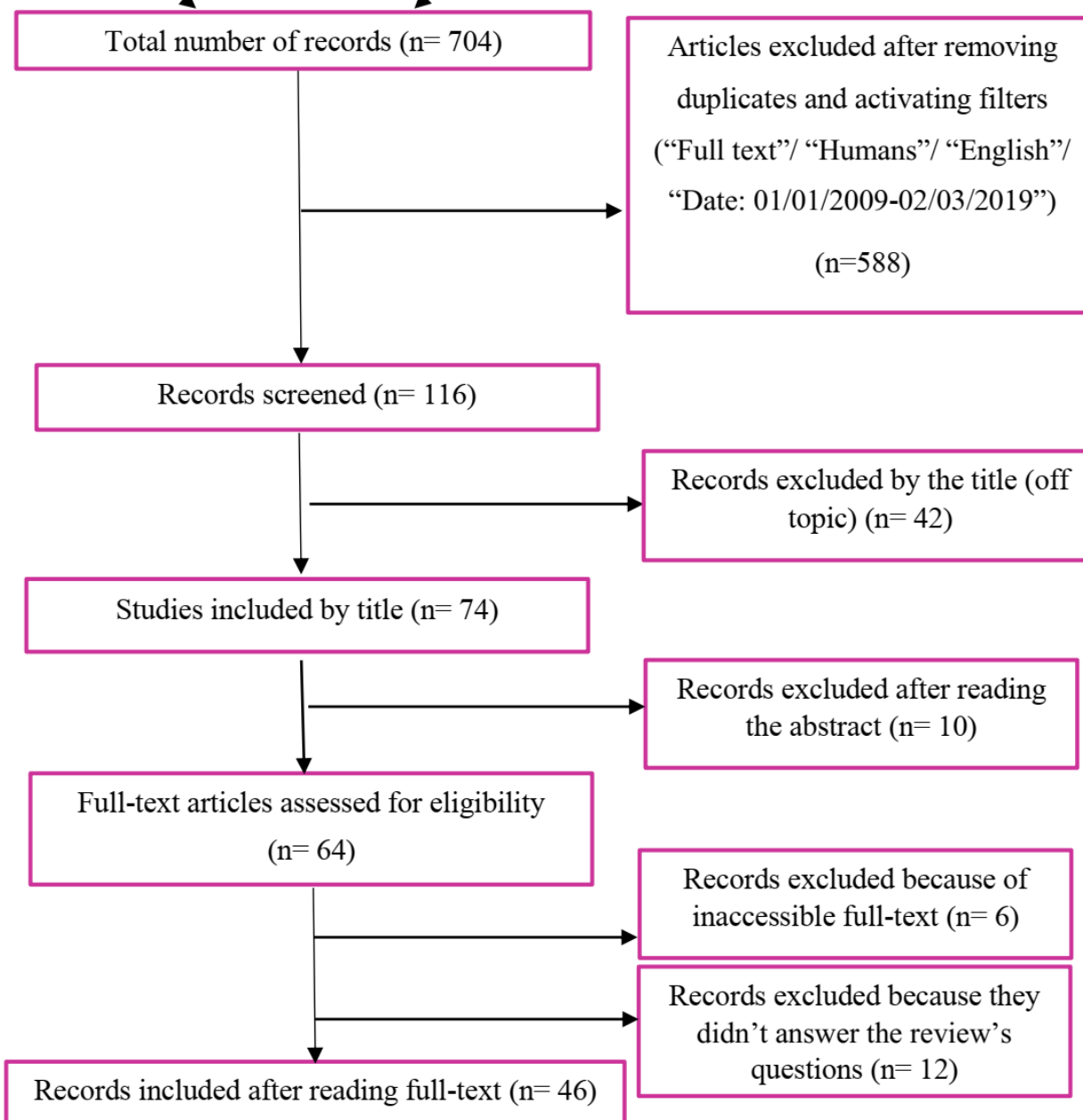

Fig-1: Literature search strategy according to the PRISMA guidelines

\section{Data Extraction}

Articles met the inclusion criteria were read in full. Data were extracted according to a preestablished grid and summarizing in standardized tables.

\section{RESULTS}

A total of 46 articles (Table-1), 1101 lesions in 1089 patients were included and analyzed in this study.

The statistical analysis results were listed below based on the different descriptive variables. 
Table-1: Types of study evaluated

\begin{tabular}{|l|l|}
\hline Type of study & Number of studies (References) \\
\hline Systematic review & $2[5,6]$ \\
\hline Randomized controlled trial & $1[7]$ \\
\hline Prospective cohort study & $3[8-11]$ \\
\hline Retrospective cohort study & $11[11-21]$ \\
\hline Case series & $8[22-29]$ \\
\hline Case report & $21[30-49]$ \\
\hline
\end{tabular}

\section{Characteristics of Cystic Lesions Treated With Marsupialization or Decompression \\ Histological Diagnosis}

There were many kinds of CL of the jaws mentioned in the 46 articles, including, odontogenic keratocyst (75\%), dentigerous cyst (12,1\%), ameloblastoma $(3,5 \%)$, radicular cysts $(3,3 \%)$, juvenile paradental cysts $(0,5 \%)$, eruption cysts $(0,2 \%)$, calcifying odontogenic cyst $(0,1 \%)$, glandular odontogenic cysts $(0,1 \%)$, naso-alveolar cysts $(0,1 \%)$ and adenomatoid odontogenic cyst $(0,09 \%)$. There were 56 lesions $(5,1 \%)$ with no definite diagnosis.

\section{Site of Involvement}

Marsupialization or decompression was performed for several CL in different sites of the jaws; $76,1 \%$ were reported in the mandible and $18,8 \%$ in the maxilla (Table-2).

Table-2: Distribution of lesions by the site involved

\begin{tabular}{|l|l|l|}
\hline & Maxilla (\%) & Mandible (\%) \\
\hline Odontogenic keratocyst & 15 & 60 \\
\hline Dentigerous cyst & 2,1 & 10 \\
\hline Ameloblastoma & 0,5 & 3 \\
\hline Radicular cysts & 0,9 & 2,4 \\
\hline Juvenile paradental cysts & 0 & 0,5 \\
\hline Eruption cysts & 0,2 & 0 \\
\hline Calcifying odontogenic cyst & 0 & 0,1 \\
\hline Glandular odontogenic cysts & 0 & 0,1 \\
\hline Naso alveolar cysts & 0,1 & 0 \\
\hline Adenomatoid odontogenic cysts & 0,09 & 0 \\
\hline Total & 18,8 & 76,1 \\
\hline
\end{tabular}

\section{Treatment Modality}

Six therapeutic modalities were analyzed in Figure-2. Marsupialization or decompression had been used alone or combined with other surgical treatments in a second surgical stage. The other treatments included enucleation, curettage, bone resection, application of carnoy's solution and bone graft.

In some cases, orthodontic treatment was indicated to preserve impacted teeth associated cystic lesions.

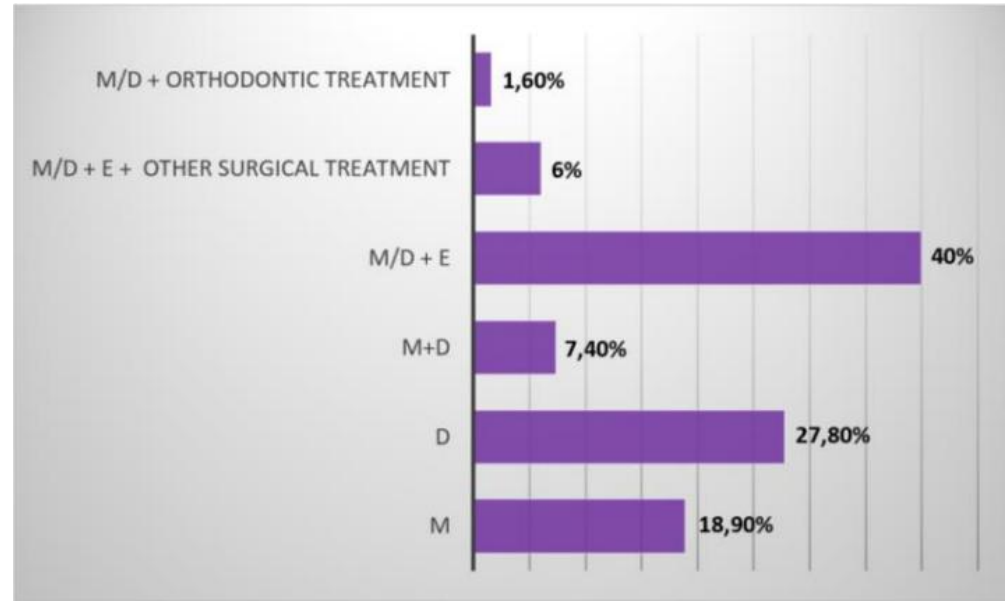

Fig-2: Distribution of patients according to therapeutic modality M: marsupialization, D: decompression, E: enucleation 


\section{Devices for Treatment}

There were many kinds of devices (Figure-3) when performing marsupialization or decompression, including different tube, gauze, obturator and others. The tube could be made by polyethylene, silastic, resin and rubber. Gauze referred to iodoform gauze impregnated with various substances such as pastes, petroleum jelly or solutions. Obturators were often made from acrylic resin.

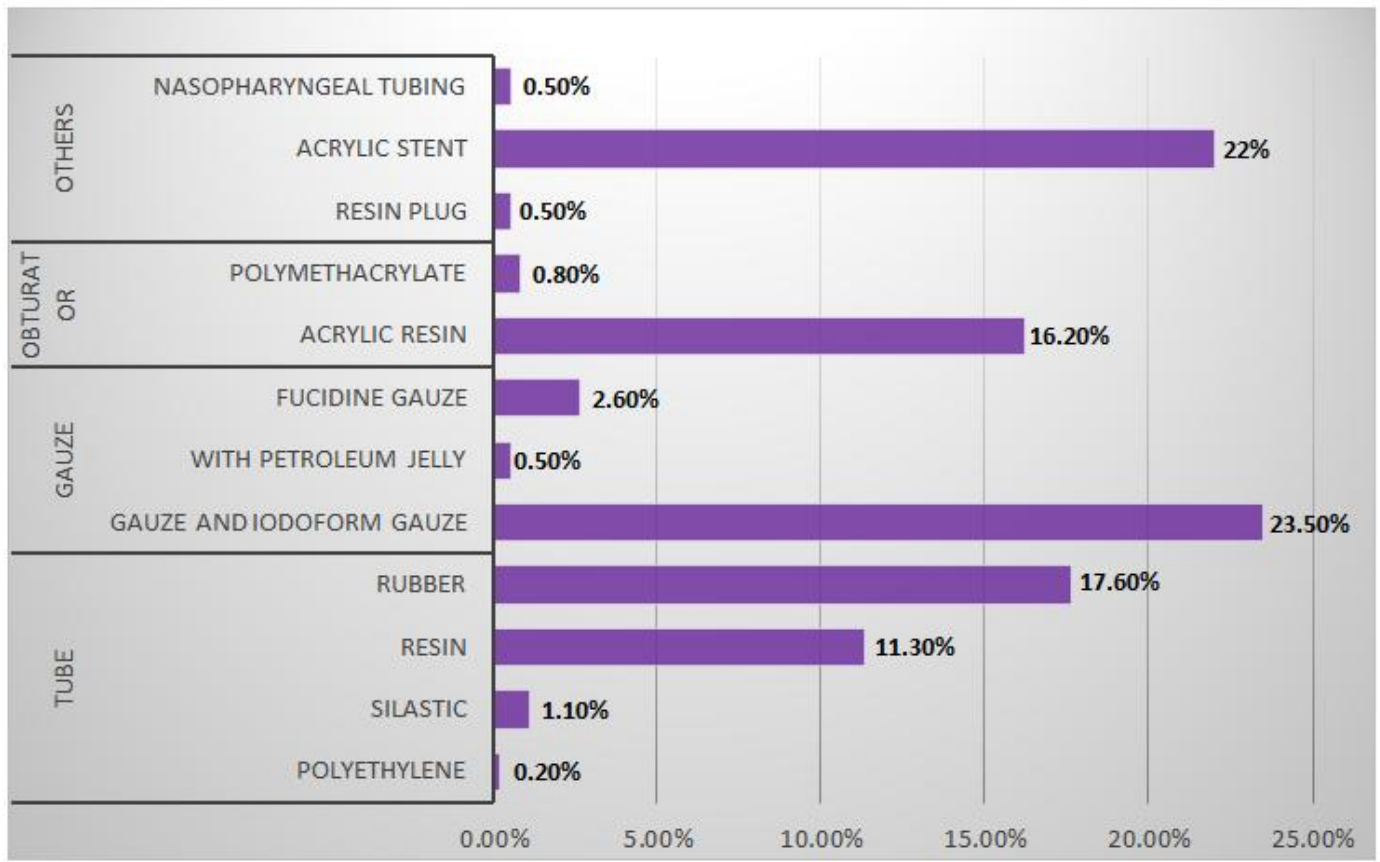

Fig-3: Analysis on devices for treatment

\section{Duration of decompression}

The duration of decompression ranged from 3 to 24 months with a mean period of 10 months.

\section{Recurrence}

Recurrence was found in only 66 cases $(6 \%)$ that were diagnosed as an OKC. Marsupialization or decompression was used again or enucleation with curettage or bone resection, had to be done after first recurrence.

\section{Data Related To Orthodontic Treatment}

In the present review, 10 published articles dealt with the combined use of marsupialization of the CLJ and orthodontic treatment. Among the 1089 patients, only $14(1,3 \%)$ had received orthodontic treatment after marsupialization or decompression.

The purpose of associating orthodontic treatment with marsupialization was:

- Traction of cystic lesion-associated impacted permanent teeth which did not erupt spontaneously after marsupialization

- Space opening or maintaining.

- To correct teeth position after marsupialization

\section{DISCUSSION}

Marsupialization or decompression has been accepted as conservative and non-invasive surgical option for the treatment of benign cystic lesions of the jaws. It aims to reduce the size of the cyst: opening the cyst eliminates its osmotic pressure and bone apposition gradually occurs at the site previously occupied by the epithelial covering of the cyst [50].

This conservative treatment was most often used in the four common cystic lesions (OKC, dentigerous cysts, radicular cysts, and cystic ameloblastoma) in the jaws. The treatment could also be used in other cystic lesions like nasoalveolar cyst, calcifying and glandular odontogenic cyst from the articles reported.

When it comes to site of involvement, this review showed that such cystic lesion may occur at different sites of maxilla and mandible. The large cystic lesions were occasionally seen on maxilla with sinus involved and on mandible with all the teeth and even ramus involved. These results are in agreement with Hou et al., findings [51].

Marsupialization had been used alone, or followed by second stage surgery (enucleation with or without adjunctive measures). It is more used alone in dentigerous cysts and radicular cysts, since it can obtain good results in such lesions. The secondary treatments were often seen in odontogenic keratocyst and cystic ameloblastoma due to their high recurrence rate and local aggressiveness $[52,51]$. 
According to the present study, there were different devices used in the treatment including tubes, gauzes, and obturators. Tube needs irrigation twice a day, obturator needs shrinking every recall time, and gauze needs changing every other week.

The combination of marsupialization with orthodontic treatment is a conservative, efficient protocol that promotes the eruption of cyst-associated teeth even if they are deeply impacted, crowded, or have a dilacerated root [53]

From the results, it showed that marsupialization or decompression had a lot of advantages: Firstly, it can minimize the cyst. Secondly, it can promote the eruption of the involved teeth and maintain the developing dentition.

Thirdly, when compared with the oftenmutilating radical primary cystectomies or resection methods, it can minimize the risk of damage to important anatomical tissue nearby, including inferior alveolar nerve and sinus, and the damage to pathologic fracture of mandible. Lastly, it can minimize the damage to bone tissue and stimulate osteogenesis.

However, there are also some disadvantages of the treatment. Firstly, it is a long healing period and the discomfort of the patient is obvious at the early stages of marsupialization. It requires cooperation from patients or parents, which plays a major role in the success rate of this treatment plan. Secondly, the cyst lining is not removed entirely, so only a part of it is examined histologically. Thirdly, a longer follow-up period is required in some cases to make sure the eruption of involving teeth and associated recurrence with this treatment.

\section{Conclusion}

To summarize, marsupialization or decompression could be performed as a single surgical procedure or combined with other treatment modalities. It has been accepted and used as a conservative surgical option for the management of benign cystic lesions of the jaw. The long-term observation confirmed the effectiveness of the treatment.

\section{REFERENCES}

1. Cysts and tumors of the jaws treated by marsupialization: A description of 4 clinical cases [Internet]. [cité 18 nov 2019]. Disponible sur: https://www.ncbi.nlm.nih.gov/pmc/articles/PMC6 645260/

2. Pogrel MA. Treatment of keratocysts: the case for decompression and marsupialization. $\mathrm{J}$ Oral Maxillofac Surg Off J Am Assoc Oral Maxillofac Surg. nov 2005;63(11):1667-73.

3. Fathi AL-Omar AA. Elmorsy K. Treatment of a large maxillary cyst with marsupialization (case report). Oral Health Care [Internet]. 2018 [cité 19 nov 2019];3(1). Disponible sur: https://www.oatext.com/treatment-of-a-largemaxillary-cyst-with-marsupialization-casereport.php

4. Boudin F, Nie JY, Bartlett JC, Grad R, Pluye P, Dawes M. Combining classifiers for robust PICO element detection. BMC Med Inform Decis Mak. 15 mai 2010;10:29.

5. de Castro MS, Caixeta CA, de Carli ML, Ribeiro Júnior NV, Miyazawa M, Pereira AAC. Conservative surgical treatments for nonsyndromic odontogenic keratocysts: a systematic review and meta-analysis. Clin Oral Investig. juin 2018;22(5):2089-101.

6. Wushou A, Zhao YJ, Shao ZM. Marsupialization is the optimal treatment approach for keratocystic odontogenic tumour. J Cranio-Maxillo-fac Surg Off Publ Eur Assoc Cranio-Maxillo-fac Surg. oct 2014;42(7):1540-4.

7. Li M, Zhang X, Li Z, An J, Qian M. Clinical research of jaw marsupialization by applying obturator made by hot pressure casting technique. 29 févr 2016;9:1850-6.

8. Shudou H, Sasaki M, Yamashiro T, Tsunomachi S, Takenoshita Y, Kubota Y. Marsupialisation for keratocystic odontogenic tumours in the mandible: longitudinal image analysis of tumour size using $3 \mathrm{D}$ visualised CT scans. Int J Oral Maxillofac Surg. mars 2012;41(3):290-6.

9. Asutay F, Atalay Y, Turamanlar O, Horata E, Burdurlu MÇ. Three-Dimensional Volumetric Assessment of the Effect of Decompression on Large Mandibular Odontogenic Cystic Lesions. J Oral Maxillofac Surg Off J Am Assoc Oral Maxillofac Surg. juin 2016;74(6):1159-66.

10. Lizio G, Tomaselli L, Landini L, Marchetti C. Dentigerous cysts associated with impacted third molars in adults after decompression: a prospective survey of reduction in volume using computerised analysis of cone-beam computed tomographic images. Br J Oral Maxillofac Surg. sept 2017;55(7):691-6.

11. Yahara Y, Kubota Y, Yamashiro T, Shirasuna K. Eruption prediction of mandibular premolars associated with dentigerous cysts. Oral Surg Oral Med Oral Pathol Oral Radiol Endod. juill 2009;108(1):28-31.

12. Iatrou I, Theologie-Lygidakis $\mathrm{N}$, Leventis $\mathrm{M}$. Intraosseous cystic lesions of the jaws in children: a retrospective analysis of 47 consecutive cases. Oral Surg Oral Med Oral Pathol Oral Radiol Endod. avr 2009;107(4):485-92.

13. Anavi Y, Gal G, Miron H, Calderon S, Allon DM. Decompression of odontogenic cystic lesions: clinical long-term study of 73 cases. Oral Surg Oral Med Oral Pathol Oral Radiol Endod. août 2011;112(2):164-9. 
14. Zhao Y, Liu B, Han QB, Wang SP, Wang YN. Changes in bone density and cyst volume after marsupialization of mandibular odontogenic keratocysts (keratocystic odontogenic tumors). J Oral Maxillofac Surg Off J Am Assoc Oral Maxillofac Surg. mai 2011;69(5):1361-6.

15. Lizio G, Corinaldesi G, Bianchi A, Marchetti C. Successful resolution of juvenile paradental cysts after marsupialization in five consecutive patients. Aust Dent J. déc 2011;56(4):427-32.

16. Lizio G, Sterrantino AF, Ragazzini S, Marchetti C. Volume reduction of cystic lesions after surgical decompression: a computerised three-dimensional computed tomographic evaluation. Clin Oral Investig. sept 2013;17(7):1701-8.

17. Qian WT, Ma ZG, Xie QY, Cai XY, Zhang Y, Yang C. Marsupialization facilitates eruption of dentigerous cyst-associated mandibular premolars in preadolescent patients. J Oral Maxillofac Surg Off J Am Assoc Oral Maxillofac Surg. nov 2013;71(11):1825-32.

18. Song IS, Park HS, Seo BM, Lee JH, Kim MJ. Effect of decompression on cystic lesions of the mandible: 3-dimensional volumetric analysis. $\mathrm{Br} \mathrm{J}$ Oral Maxillofac Surg. nov 2015;53(9):841-8.

19. Liang YJ, He WJ, Zheng PB, Liao GQ. Inferior alveolar nerve function recovers after decompression of large mandibular cystic lesions. Oral Dis. juill 2015;21(5):674-8.

20. Oliveros-Lopez L, Fernandez-Olavarria A, TorresLagares D, Serrera-Figallo M-A, Castillo-Oyagüe $\mathrm{R}$, Segura-Egea JJ. Reduction rate by decompression as a treatment of odontogenic cysts. Med Oral Patol Oral Cirugia Bucal. 1 sept 2017;22(5):e643-50.

21. Sun R, Cai Y, Wu Y, Zhao JH. Marsupialization facilitates movement of the cystic lesionassociated deeply impacted mandibular third molar in spite of its mature roots. Med Oral Patol Oral Cirugia Bucal. 1 sept 2017;22(5):e625-9.

22. Kirtaniya BC, Sachdev V, Singla A, Sharma AK. Marsupialization: a conservative approach for treating dentigerous cyst in children in the mixed dentition. J Indian Soc Pedod Prev Dent. sept 2010;28(3):203-8.

23. Borgonovo AE, Di Lascia S, Grossi G, Maiorana C. Two-stage treatment protocol of keratocystic odontogenic tumour in young patients with GorlinGoltz syndrome: marsupialization and later enucleation with peripheral ostectomy. A 5-yearfollow-up experience. Int $\mathrm{J}$ Pediatr Otorhinolaryngol. déc 2011;75(12):1565-71.

24. Deboni MCZ, Brozoski MA, Traina AA, Acay RR, Naclério-Homem M da G. Surgical management of dentigerous cyst and keratocystic odontogenic tumor in children: a conservative approach and 7-year follow-up. J Appl Oral Sci Rev FOB. avr 2012;20(2):282-5.
25. Dolanmaz D, Etoz OA, Pampu A, Kalayci A, Gunhan O. Marsupialization of unicystic ameloblastoma: a conservative approach for aggressive odontogenic tumors. Indian J Dent Res Off Publ Indian Soc Dent Res. oct 2011;22(5):709 $-12$.

26. Tabrizi R, Özkan BT, Dehgani A, Langner NJ. Marsupialization as a treatment option for the odontogenic keratocyst. J Craniofac Surg. sept 2012;23(5):e459-461.

27. Uloopi KS, Shivaji RU, Vinay C, Pavitra, Shrutha SP, Chandrasekhar R. Conservative management of large radicular cysts associated with non-vital primary teeth: a case series and literature review. J Indian Soc Pedod Prev Dent. mars 2015;33(1):536.

28. Gurler G, Yilmaz S, Delilbasi C, Dilaver E, Yuzbasioglu E, Patir-Munevveroglu A. Conservative surgical treatment of the jaw cysts in children: Case study of five patients. Niger J Clin Pract. sept 2017;20(9):1216-20.

29. Gendviliene I, Legrand P, Nicolielo LFP, Sinha D, Spaey Y, Politis C. Conservative management of large mandibular dentigerous cysts with a novel approach for follow up: Two case reports. Stomatologija. 2017;19(1):24-32.

30. Alpy A, Tournaire L, Vaysse F, Marchal-Sixou C, Lhomme A, Courtois B. Interest of decompression in orthodontics: Case report of a keratocyst during childhood. Int Orthod. juin 2017;15(2):238-50.

31. Emam HA, Smith J, Briody A, Jatana CA. Tube Decompression for Staged Treatment of a Calcifying Odontogenic Cyst-A Case Report. J Oral Maxillofac Surg Off J Am Assoc Oral Maxillofac Surg. sept 2017;75(9):1915-20.

32. Aoki N, Ise K, Inoue A, Kosugi Y, Koyama C, Iida M. Multidisciplinary approach for treatment of a dentigerous cyst - marsupialization, orthodontic treatment, and implant placement: a case report. J Med Case Reports. 10 oct 2018;12(1):305.

33. $\mathrm{Hu} \mathrm{YH}$, Chang YL, Tsai A. Conservative treatment of dentigerous cyst associated with primary teeth. Oral Surg Oral Med Oral Pathol Oral Radiol Endod. déc 2011;112(6):e5-7.

34. 34. Cakarer S, Selvi F, Isler SC, Keskin C. Decompression, enucleation, and implant placement in the management of a large dentigerous cyst. J Craniofac Surg. mai 2011;22(3):922-4.

35. Morais de Melo W, Pereira-Santos D, Sonoda CK, Hochuli-Vieira E. Decompression for management of keratocystic odontogenic tumor in the mandible. J Craniofac Surg. nov 2012;23(6):e639-640.

36. Garde JB, Kulkarni AU, Dadhe DP, Deshmukh VB. Use of decompression tubes in the management of excessively large odontogenic keratocyst. BMJ Case Rep. 27 mars 2012;2012. 
37. Carneiro JT, Carreira ASD, Félix VB, da Silva Tabosa AK. Pathologic fracture of jaw in unicystic ameloblastoma treated with marsupialization. J Craniofac Surg. nov 2012;23(6): e537-539.

38. Tomita Y, Kuroda S, Takahashi T, Ohura R, Tanaka E. Orthodontic occlusal reconstruction after conservative treatment of unicystic ameloblastoma in an adolescent patient: 10-year follow-up. Am J Orthod Dentofac Orthop Off Publ Am Assoc Orthod Its Const Soc Am Board Orthod. sept 2013;144(3):466-70.

39. Hyun HK, Hong SD, Kim JW. Recurrent keratocystic odontogenic tumor in the mandible: a case report and literature review. Oral Surg Oral Med Oral Pathol Oral Radiol Endod. août 2009;108(2):e7-10.

40. Sazgar AA, Sadeghi M, Yazdi AK, Ojani L. Transnasal endoscopic marsupialization of bilateral nasoalveolar cysts. Int J Oral Maxillofac Surg. nov 2009;38(11):1210-1.

41. Shivaprakash PK, Rizwanulla T, Baweja DK, Noorani HH. Save-a-tooth: conservative surgical management of dentigerous cyst. J Indian Soc Pedod Prev Dent. mars 2009;27(1):52-7.

42. Berti S de A, Pompermayer AB, Couto Souza PH, Tanaka OM, Westphalen VPD, Westphalen FH. Spontaneous eruption of a canine after marsupialization of an infected dentigerous cyst. Am J Orthod Dentofac Orthop Off Publ Am Assoc Orthod Its Const Soc Am Board Orthod. mai 2010;137(5):690-3.

43. Bozdogan E, Cankaya B, Gencay K, Aktoren O. Conservative management of a large dentigerous cyst in a 6-year-old girl: a case report. J Dent Child Chic Ill. déc 2011;78(3):163-7.

44. de Melo WM, Pereira-Santos D, Brêda-Júnior MA, Hochuli-Vieira E, Gabrielli MAC, Gabrielli MFR. Conservative management of a large keratocystic odontogenic tumor in the maxilla. $\mathrm{J}$ Craniofac Surg. mai 2012;23(3):e184-186.
45. Marcotullio D, Iannella G, Zelli M, Marinelli C, Magliulo G. Rare and massive odontogenic parakeratotic cyst treated by endoscopic sinus surgery: a case report. J Med Case Reports. 5 sept 2014;8:293

46. de Paulo LFB, Oliveira MTF, Rodrigues ÁR, Zanetta-Barbosa D. Treatment of an extensive unicystic ameloblastoma in a 7-year-old child: the best approach? Br J Oral Maxillofac Surg. mars 2015;53(3):292-4

47. Xavier SP, de Mello-Filho FV, Rodrigues WC, Sonoda CK, de Melo WM. Conservative approach: using decompression procedure for management of a large unicystic ameloblastoma of the mandible. J Craniofac Surg. mai 2014;25(3):10124.

48. Maltoni I, Santucci G, Maltoni M, Zoli L, Perri A, Gracco A. Recovering teeth from a large dentigerous cyst: A case report. Int Orthod. juin 2015;13(2):232-44.

49. Sheikh J, Cohen MD, Ramer N, Payami A. Ghost Cell Tumors. J Oral Maxillofac Surg. 1 avr 2017;75(4):750-8.

50. Guruprasad Y, Singh D. Is marsupialization still the treatment of choice for large unicystic lesions of the jaws? Med J Dr Patil Univ. 18 nov 2014;7:825-6.

51. Hou R, Zhou H. Articles of marsupialization and decompression on cystic lesions of the jaws: A literature review. J Oral Maxillofac Surg Med Pathol. 1 oct 2013;25(4):299-304.

52. Briki S, Elleuch W, Karray F, Abdelmoula M, Tanoubi I. Cysts and tumors of the jaws treated by marsupialization: A description of 4 clinical cases. J Clin Exp Dent. 1 juin 2019;11(6):e565-9.

53. Abu-Mostafa N, Abbasi A. Marsupialization of a large dentigerous cyst in the mandible with orthodontic extrusion of three impacted teeth. A case report. J Clin Exp Dent. 1 sept 2017;9(9):e1162-6. 